(2)

\title{
Epithelial growth over the optic surface of the type I Boston Keratoprosthesis: histopathology and implications for biointegration
}

This article was published in the following Dove Press journal:

Clinical Ophthalmology

16 September 2010

Number of times this article has been viewed

\section{Yousuf M Khalifa \\ Don Davis \\ Nick Mamalis \\ Majid Moshirfar \\ Moran Eye Center, University of Utah, Salt Lake City, UT, USA}

Correspondence: Majid Moshirfar 65 Mario Capecchi Way, Salt Lake City, UT 84I32, USA

Tel $+\mid$ 80| 58| 2352

Fax + I 80I 58I3357

Email majid.moshirfar@hsc.utah.edu
Abstract: We report the histopathology of epithelial overgrowth in the Boston type I keratoprosthesis. The epithelium shows an inconsistent number of layers and basement membrane and goblet cells are absent. Epithelialization of the keratoprosthesis optic would have multiple advantages, but the limitation of vision makes tolerating the overgrowth difficult.

Keywords: keratoprosthesis, cornea, corneal transplant, biocompatibility, biointegration epithelium

\section{To the editor}

The Boston Keratoprosthesis (KPro) was approved in 1992 by the US Food and Drugs Administration as a means to rehabilitate corneal blindness in eyes that are poor candidates for traditional penetrating keratoplasty. ${ }^{1}$ Failed corneal graft is the mainstay indication for KPro implantation, but some have advocated expanding the clinical indications to include pediatric corneal opacities, ${ }^{2}$ limbal stem cell deficiency, ${ }^{3}$ severe ocular trauma, ${ }^{4}$ and herpes zoster keratitis. ${ }^{5}$ Composed of poly(methyl methacrylate) (PMMA), the KPro has demonstrated good biocompatibility with corneal stroma, but there are limited data on the biocompatibility of the KPro with corneal epithelium and endothelium. ${ }^{6}$

Reported complications of the KPro include retroprosthetic membrane, infectious and sterile endophthalmitis, corneal melt, extrusion, and retinal detachment. ${ }^{7-9}$ In one series, $44 \%$ of eyes had retroprosthetic membrane requiring yttrium aluminium garnet membranectomy, $38 \%$ had a persistent epithelial defect requiring lateral tarsorrhaphy, $18 \%$ had elevated intraocular pressure, and $16 \%$ had corneal melt. ${ }^{10} \mathrm{We}$ have noted epithelial growth over the KPro optic in some of our patients, and we are not aware of previous reports describing this occurrence or its incidence. We report a case of recurrent epithelial growth over the Boston KPro optic that degraded vision and provide histopathology analysis.

\section{Case description History}

A 39-year-old male with a history of renal transplantation had subsequent cytomegalovirus retinitis in both eyes while on immunosuppression and also herpes zoster ophthalmicus in his left eye. He developed corneal scarring, and over the course of 9 years, he rejected four full-thickness corneal transplants in the left eye. In 2006, he underwent an uncomplicated implantation of an aphakic type 1 KPro. He remained 
stable through 2009 with 20/70 best-corrected visual acuity, but in early 2010, he developed an epithelial growth over the optic of the KPro that caused his vision to deteriorate to 20/400. The epithelium was removed with a moistened cotton-tip applicator at the slit lamp, and his vision promptly returned to 20/70. A bandage contact lens was placed over the eye, and the patient was continued on topical antibiotics.

\section{Examination}

Ten days later he returned with 20/300 vision in the left eye. External examination was within normal limits. Slit lamp examination showed a white and quiet conjunctiva. The cornea was quiet without necrosis or melt. There was no extrusion of the KPro, but epithelial regrowth over the KPro optic was noted (Figure 1). The anterior chamber was quiet without evidence of a retroprosthetic membrane.

\section{Intervention treatment}

The recurrence was managed under a surgical microscope using a $15^{\circ}$ blade to scrape the epithelium completely off the optic. A bandage contact lens was placed over the KPro.

\section{Pathology}

A piece of tissue measuring $1.0 \times 0.8 \times 0.3 \mathrm{~mm}$ was submitted in formalin. The tissue was embedded into a paraffin block and sectioned with $5-\mu$ cuts. The cuts were fixed to glass slides and stained with either standard hematoxylin and eosin or standard periodic acid-Schiff(PAS) preparation. Specimen slides revealed a nonkeratinized epithelium that was folded upon itself (Figure 2). The epithelium was composed of 3-5 layers of cells, variable in each area of the slide. No dysplastic nuclei or pleomorphic cells were noted, and epithelium

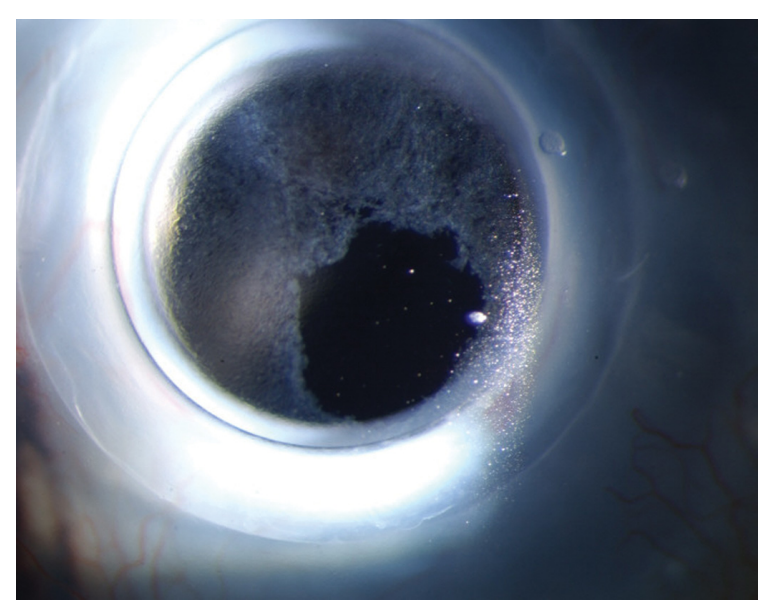

Figure I Slit lamp photograph of the type I Boston Keratoprosthesis with epithelial growth over the optic.

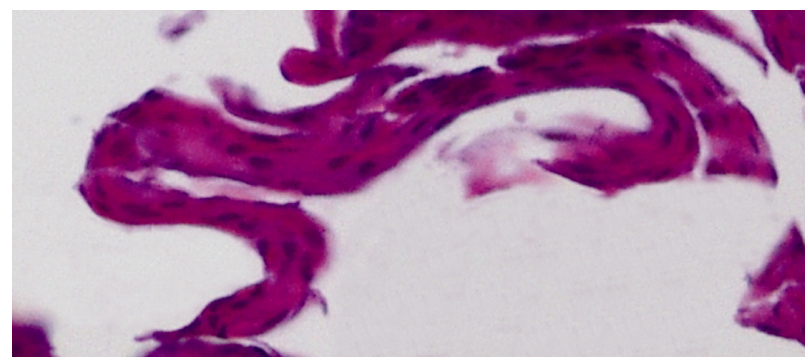

Figure 2 Hematoxylin and eosin stain of epithelial growth removed from the type I Boston Keratoprosthesis optic surface showing a variable thickness and number of cell layers, no vascular structures, no goblet cells, and no basement membrane.

matured normally. No basement membrane or goblet cells were noted with PAS staining.

\section{Follow-up}

The patient maintained 20/70 vision for the next 5 months without recurrence of the epithelial overgrowth. In June 2010, he complained of deteriorating vision to 20/300, and epithelial growth over the optic was noted and managed in the same fashion.

\section{Discussion Pathology}

Giant cells are frequently noted on the surface of PMMA intraocular lenses. ${ }^{11}$ Epithelial migration over PMMA devices is a rare occurrence due to the scarcity of corneal or conjunctival epithelial exposure to implantable ophthalmic devices. Epithelium secretes basement membrane in order to adhere or migrate to a surface. With a lack of basement membrane on the specimen and the tight epithelial adherence to the PMMA KPro, we surmise that the epithelial basement membrane may have incorporated within the PMMA material.

The histopathology of the scraped epithelium shows no goblet cells, which points toward a corneal epithelial origin. In addition, there are no blood vessels, which is likely due to the lack of inflammatory impetus. The epithelial sheet shows a varying, inconsistent number of cell layers, which limited the patient's visual acuity.

\section{Literature review}

Ament et $\mathrm{al}^{6}$ studied the in vitro interaction between an immortalized human corneal-limbal epithelial (HCLE) cell line and PMMA, and they found that the PMMA was cytotoxic to the HCLE cells. In this report, we describe recurrent epithelial growth over the KPro PMMA optic in vivo that severely compromised the patient's vision, and to our knowledge, this is the first description of this occurrence in the Boston Kerato- 
prosthesis. This occurrence is not unusual in the management of KPro patients, but this topic has received little attention, despite the fact that it frequently hinders vision.

\section{Outcome}

Epithelial overgrowth is easily managed with scraping as described in this report. We recommend carrying the scraping beyond the edges of the optic to help prevent recurrence. A more definitive management may include use of antiproliferative agents such as mitomycin $\mathrm{C}$, but we have been hesitant to incorporate this measure because of the risk of melt.

\section{Opinion}

The corneal epithelium must be of uniform thickness to provide optical clarity. This case illustrates the ability of PMMA to support epithelial proliferation without the obtrusion of conjunctival goblet cells or vascularization. The key for successful epithelialization of the KPro optic is developing methods to guide the epithelium into a regular sheet of cells; thus, the vision would not be adversely affected, and the risk of infection and inflammation is minimized.

\section{Disclosure}

The authors report no conflicts of interest in this work.

\section{References}

1. Dohlman CH. Background of the present Boston Kpro I for graft failures. Boston Keratoprosthesis Update. 2004;1:1-2.

2. Aquavella JV, Gearinger MD, Akpek EK, McCormick GJ. Pediatric keratoprosthesis. Ophthalmology. 2007;114(5):989-994.

3. Chew HF, Ayres BD, Hammersmith KM, et al. Boston keratoprosthesis outcomes and complications. Cornea. 2009;28(9):989-996.

4. Harissi-Dagher M, Dohlman CH. The Boston keratoprosthesis in severe ocular trauma. Can J Ophthalmol. 2008;43(2):165-169.

5. Pavan-Langston D, Dohlman CH. Boston keratoprosthesis treatment of herpes zoster neurotrophic keratopathy. Ophthalmology. 2008;115 Suppl 2:S21-S23.

6. Ament JD, Spurr-Michaud SJ, Dohlman CH, Gipson IK. The Boston keratoprosthesis: comparing epithelial cell compatibility with titanium and PMMA. Cornea. 2009;28(7):808-811.

7. Zerbe BL, Belin MW, Ciolino JB; Boston Type 1 Keratoprosthesis Study Group. Results from the multicenter Boston Type 1 Keratoprosthesis Study. Ophthalmology. 2006;113(10):1779-1784.

8. Yaghouti F, Nouri M, Abad JC, Power WJ, Doane MG, Dohlman CH. Keratoprosthesis: preoperative prognostic categories. Cornea. 2001;20(1):19-23.

9. Bradley JC, Hernandez EG, Schwab IR, Mannis MJ. Boston type 1 keratoprosthesis: the University of California Davis experience. Cornea. 2009;28(3):321-327.

10. Aldave A, Kamal KM, Vo RC, Yu F. The Boston type I keratoprosthesis: improving outcomes and expanding indications. Ophthalmology. 2009;116(4):640-651.

11. Ferrer C, Abu-Mustafa SK, Ali JL. Scanning electron microscopy analysis of a sputnik-like intraocular lens 28 years after implantation. J Refract Surg. 2009;25(9):788-791.
Clinical Ophthalmology

\section{Publish your work in this journal}

Clinical Ophthalmology is an international, peer-reviewed journal covering all subspecialties within ophthalmology. Key topics include: Optometry; Visual science; Pharmacology and drug therapy in eye diseases; Basic Sciences; Primary and Secondary eye care; Patient Safety and Quality of Care Improvements. This journal is indexed on

Submit your manuscript here: http://www.dovepress.com/clinical-ophthalmology-journal

\section{Dovepress}

PubMed Central and CAS, and is the official journal of The Society of Clinical Ophthalmology (SCO). The manuscript management system is completely online and includes a very quick and fair peer-review system, which is all easy to use. Visit http://www.dovepress.com/ testimonials.php to read real quotes from published authors. 